\title{
Congenital Muscular Torticollis
}

\author{
Lt Col Shyam S Jaiswal", Maj KS Brar+, Lt Col S Ramesh"
}

MJAFI 2005; 61 : 277-278

Key Word: Congenital muscular torticollis

\section{Introduction}

C ongenital, muscular torticollis is a painless condition usually presenting during infancy. It is seen in 0.3 to $0.5 \%$ of all live births and generally involves unilateral sternocleidomastoid muscle contraction [I]. The most likely causes include intra uterine malposition and birth trauma. We present a case of congenital muscular troticollis who reported at the age of 10 years and has been successfully corrected.

\section{Case Summary}

A ten year old girl presented with deformity of the face and neck which had been noticed soon after her birth and had progressively increased. The history was suggestive of trauma at the time of birth as the presentation was breech and extraction had been carried out. Examination showed an averagely built and nourished girl with head tilted to the right side and face rotated to the opposite side (Fig 1). The right sternocleidomastoid was thickened and cord like. Movements of the cervical spine, especially lateral rotation, were markedly restricted. There was no facial asymmetry. Other general and systemic examination was unremarkable. Hips and lower extremities were normal. Radiographs of the cervical spine did not reveal any bony abnormality. The patient was prepared and taken up for surgery under general anaesthesia. A transverse incision was given $2.5 \mathrm{~cm}$ above the medial end of the right clavicle and the platysma was incised. Both the heads of the sternocleidomastoid were defined and then divided, under vision with electro cautery together with the deep cervical fascia, and allowed to retract. The scalenus anterior muscle was found to be shortened and was also divided, after identifying and safe guarding the phrenic nerve, to obtain full correction of the deformity. The wound was closed in layers, without drain. The skin was closed using subcuticular 3/0 vicryl. Post operatively, the patient was immobilized in the corrected position using a plaster of paris cast which was removed after one week and replaced with an adjustable torticollis brace (Fig 2). Simultaneously the patient was started on a vigorous physiotherapy regimen, involving manipulation of the head and neck through a full range of movements, four times a day. These exercises and application of brace were continued for a period of 3 months after the surgery. The patient has shown a satisfactory response to treatment and is free of recurrence after 18 months of followup (Fig 3).

\section{Discussion}

Congenital muscular torticollis is a condition of debatable etiology and management. It is generally regarded as being due to birth injury, causing either rupture of the fibres of the sternocleidomastoid or of the vessels supplying it. Degeneration of the affected fibres occurs and is followed by fibrous tissue replacement which results in contracture or failure of growth of the muscle. If the condition is untreated, the other muscles on the affected side and the deep fascia become shortened as well [2]. This was noticed in this case wherein the shortened scalenus anterior muscle had to be divided to obtain full correction of the deformity. An alternative view describes it as a developmental aplasia of the muscles and other soft tissue structures on the affected side of the neck [2]. A high incidence of associated hip dysplasia [3] and ipsilateral mandibular hypoplasia [4] have also been reported.

The diagnosis is clinical, though the role of ultrasonographic imaging in diagnosis and monitoring of patients of congenital muscular torticollis has been reported [5]. A thorough evaluation of the child must be undertaken to exclude other causes of abnormal neck posture such as congenital or acquired conditions of the cervical spine, ocular conditions like squints and visual field defects, infections of the ear and throat and intracranial lesions. Before starting treatment these patients may be classified into one of the following three clinical groups-

(a) palpable sternomastoid tumour

(b) muscular torticollis (thickening and tightness of the steromastoid muscle)

"Reader, Department of Surgery, Armed Forces Medical College, Pune-40., ${ }^{+}$Graded Specialist(Medicine), ${ }^{\#}$ Commanding Officer, Military Hospital, Alwar, Rajasthan.

Received : 31.05.2003; Accepted : 16.10.2003 


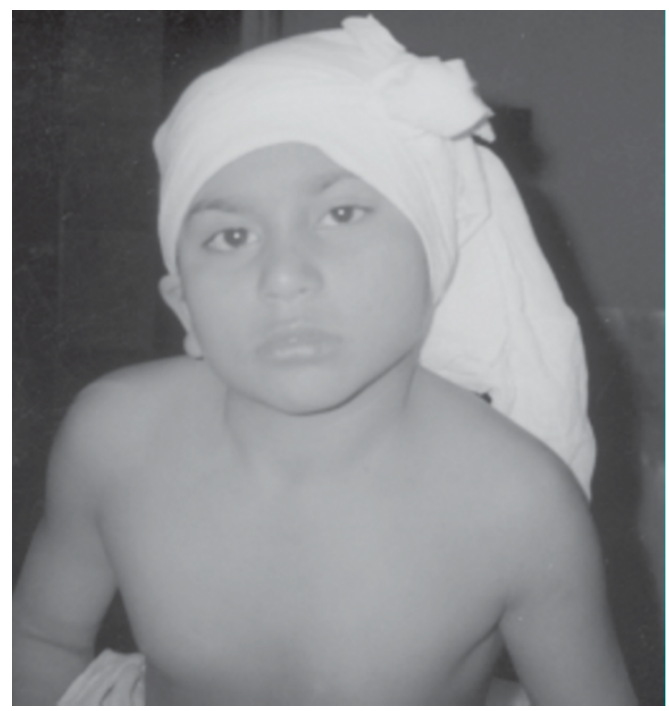

Fig. 1 : Pre-operative appearance

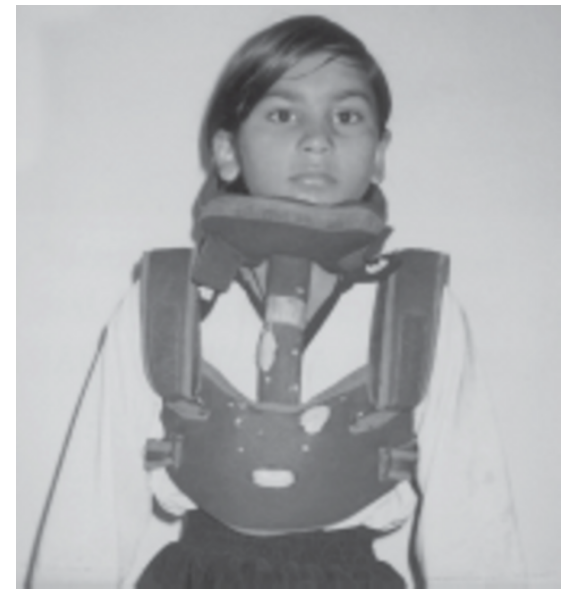

Fig. 2: Appearance during early post operative period with torticollis brace

(c) postural torticollis (torticollis but no muscle tightness or tumour)

The patients in groups "a" and "b" are more likely to require surgical treatment [6]. The main treatment modalities are physiotherapy and surgery. A regimen of controlled manual stretching exercises is associated with positive outcomes in over $90 \%$ of the cases, if the treatment is started before the age of one year [6].

Surgical treatment is usually required when diagnosis is delayed or following failure of conservative management. It must be undertaken before facial asymmetry and secondary changes in the cervical spine have developed. The surgical procedure entails exposure and division of both the heads of the sternocleidomaetoid. Sometimes the scalenus anterior and carotid sheath may also have to be divided to obtain full correction of the deformity [2]. Surgical release of the sternocleidomastoid by endoscopic method has been claimed to give equally

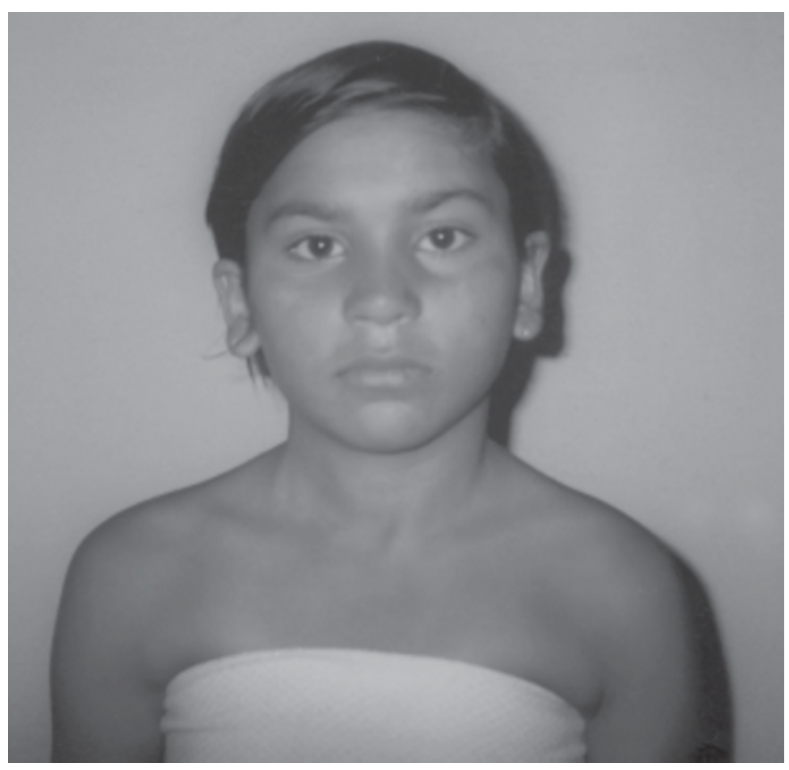

Fig. 3 : Post operative appearance after one year

good results while leaving an inconspicuous scar on the scalp [7]. Vigorous post operative physiotherapy must be continued for 3-4 months to achieve the best result [8]. The use of Botox injections to relax the tight muscle is a new form of treatment being tried by some practitioners [9].

\section{References}

1. Chawla S, Nath B, Bhatia JS. Congenital torticollis. MJAFI 2000;56:55-6.

2. Johnstone JMS, Maran AGD, Rintoul RF. Operations on the neck and salivary glands. In : Rintoul RF, editor. Farquharson's text book of opertive surgery, $7^{\text {th }}$ ed. Edinburgh: Churchill Livingstone, 1986;239

3. Morrision DL, Mac Ewen GD. Congenital muscular torticollis: observations regarding clinical findings, associated conditions and results of treatment. J Pediatr Orthop 1982;2(5) :500-5

4. HoBC, Lee EH, Singh K. Epidemiology, presentation and management of congenital muscular torticollis. Singapore Med J 1999 Nov;40(II);675-9

5. Cheng JC, Metreweli C, Chen TM, Tang S. Correlation of ultrasonographic imaging of congenital muscular torticollis with clinical assessment in infants. Ultrasound Med Biol 2000; 26(8):1237-41

6. Cheng JC, Wong MW, Tang SP, Chen TM, Shum SL, Wong EM. Clinical determinants of the outcome of manual stretching in the treatment of congenital muscular torticollis in infants. A prospective study of eight hundred and twenty one cases. J Bone Joint Surg Am 2001;83-A(5):679-87

7. Burstein FD,Cohen SR. Endoscopic surgical treatment for congenital muscular torticollis. Plast Reconstr Surg 1998; 101(1):20-6

8. Cheng JC, Tang SP. Out come of surgical treatment of congenital muscular torticollis. Clin Orthop 1999; (362):190-200

9. Luther BL.Congenital muscular torticollis. Orthop Nurs 2002 May-June; 21(3):21-7; quiz 27-9 